\title{
A game theory approach for competition and cooperation among project's subcontractors with interaction activities
}

\author{
Ashkan Hafezalkotob*, Elahe Hoseinpour and Kaveh Khalili Damghani
}

Department of Industrial Engineering, Islamic Azad University, South Tehran Branch, Tehran, Iran

\section{H R O N I C L E}

Article history:

Received: March 5, 2017

Received in revised format: May 16, 2017

Accepted: June 11, 2017

Available online:

June 12, 2017

Keywords:

Project subcontractors

Fair competition and cooperation

Cooperative and non-cooperative

game theory

Project management

Time/cost trade-off

Cost saving

\section{A B S T R A C T}

\begin{abstract}
Some projects are often performed by many subcontractors that cooperate with each other and some of them are conducted by outsourcing them to several firms; so subcontractors carry out activities in competition. Appropriate trade-off between time and cost and achieving more benefit and cost saving are objectives of both models. In this paper, it is investigated that how different subcontractors of a project can cooperate to achieve more advantages if possible and how subcontractors can compete to make the results better and find the optimum cost to minimize the time for each of them. The competition here does not mean eliminating a competitor, but the aim is to challenge the contractors in order to choose the best decision. The purpose of this study is to address the challenges in time and cost management and to find more profit allocation among subcontractors and fair competition for fair allocation as well. A model based on cooperative game theory in time/cost trade-off problem of projects is suggested and then a competition model among subcontractors based on non-cooperative game theory is proposed. A case study is represented to comprehensively illustrate the problem, the cooperative techniques of cooperative game theory, and the payoff matrix of non-cooperative model among subcontractors. Results of the proposed model reveal that subcontractors can obtain higher profit from cooperation if possible. When they outsource the project and compete with each other, they must consider the interaction activities and choose the best strategies for cost saving and gain more reward from the client. Moreover, it is found that some techniques such as Shapley value, Core, Max-Min Core, or Equal Profit Method (EPM) are able to fairly assign extra profit of cooperation, and using the payoff matrix, Nash equilibrium, and Nash bargaining helps to find the optimum point to minimize time and cost for interaction activities state.
\end{abstract}

\section{Introduction}

Many large-scale projects are usually completed by the efforts of several subcontractors that may be either compete or cooperate with each other. Some of the subcontractors can cooperate in issues such as sharing their budgets, information, resources, work volume, and time/cost trade-off. Cooperation among subcontractors often provides them more profit if possible. When subcontractors get more benefits by cooperative strategy, then they can negotiate on how to allocate the achieved benefits. Some

* Corresponding author. Tel:+98 9127785681

E-mail address: a hafez@azad.ac.ir (A. Hafezalkotob)

2017 Growing Science Ltd.

doi: $10.5267 / j . j p m .2017 .6 .002$ 
projects are outsourced to some firms and they hire several subcontractors to carry out the project activities; the subcontractors negotiate with each other to choose the best strategies which are appropriate for all of them. Cooperative game theory methods and non-cooperative game theory concepts of a project can be useful to study the cooperation and competition among the subcontractors. Thus, various solution approaches of the game theory are applied to model the subcontractors' cooperation and choose the best strategy for competition among them.

In this paper, time/cost trade off model based on the game theory methods is developed to analyze the subcontractors' behavior in a large-scale project. The paper is organized in four sections. In the next section, literature review of the cooperation and non-cooperation game theory and cooperation and competition among the subcontractors is studied. Section 3 proposes the cooperative model for time/cost trade off among the subcontractors and investigates a competition among them to choose the best strategy to achieve more awards. Section 4 gives numerical examples to demonstrate the achieved results and insights. In section 5, the conclusion and future researches are discussed.

\section{Literature review}

Game theory is classified into two categories including the non-cooperative and cooperative ones. A cooperative game is a technique in which the groups of players, e.g. the words player and subcontractor are used interchangeably, have to cooperate with each other to reach a common objective. Therefore, the game is considered as the cooperation among coalition members of players rather than individual ones. On the other hand, a non-cooperative game is considered as the one in which the players make their own decisions independently. The payoff matrix showed in section 4 belongs to the non-cooperative category. The Nash equilibrium and Nash bargaining are solution concepts of a non-cooperative game in association with two or more players, in which each player is supposed to be aware of the equilibrium strategies of the other players, and no player has anything to gain by changing only his/her own strategy. Subcontractors' behavior in a project can be either a cooperative game theory or a noncooperative game theory. There are some researches about the subcontractors in which they can utilize the cooperation benefits and fair competition advantages during a project.

Segal and Hershberger (1999) study a prisoner's dilemma game for cooperation and competition between Twins. This research is the first in a series of studies designed to address the mechanisms underlying differences in cooperation between pairs who vary in average genetic commonality. Parrod et al. (2007) study the interaction of various agents within a type of supply chain and propose degree of cooperation between the agent and the capacity of each of them to predict the effects of their behaviors. Indeed, they study the cooperation subcontracting relationship within a project supply chain. The analysis of their case study underlines the main industrial requirements and indicates the tools' effect on evaluating the effect of various cooperative behaviors. Arsenyan et al. (2015) propose a mathematical model integrating trust, coordination, co-learning, and co-innovation dimensions of collaborative product development. They shed light on the effect of different parameters on the collaboration formation as well as the revenue sharing with Nash Bargaining approach. The analysis presents the optimum strategies for each scenario. Canegallo et al. (2008) survey the effects of competition on subjects' attitude towards cooperation. They report a reducing attitude towards cooperation clearly emerges as the degree of competition increases. Therefore, if cooperation enhances well-being, the maximum degree of competition may be not efficient. Mouritsen (1999) represents strategies for a subcontractor's management control in a flexible firm.

A project consists of a set of activities which must be completed over a period of time and is intended to reach a particular objective. In deterministic circumstances, there are two important methods to schedule and coordinate the activities in a project which are the PERT (Program Evaluation Review Technique) and the CPM (Critical Path Method). In this paper, the model is established based on the CPM method to schedule the project activities. Important issues in a project management are the delay and expedition. Moreover, in private projects, there is usually a term in the subcontract which considers 
penalties and rewards for the company according to the end time of the project regarding the planned time. If the project has some interaction activities, divided among several subcontractors, time consideration of the interaction activities is so important. There are many researches in this field that some of them are presented here. Brânzei et al. (2002) study a delayed project problems in the framework of taxation problems and propose a specific allocation rule. Estévez-Fernández et al. (2007) for the first time study the allocation problem from a direct game theoretical point of view. Estévez-Fernández (2012) focuses on how to divide the total penalties and rewards in projects based on game theoretical approaches.

Lozano et al. (2013) study the cost savings that different companies may achieve when they merge their transportation requirements and present a linear model. Kadefors (2004) investigates trust effect in project relationships, between client and contractor. Cakmak and Tas (2012) suggest a model to describe the perspectives contractor firms in terms of strategic planning in Turkey. Suprapto (2015) investigates the nature of working relationships between owner and contractor in engineering and construction projects. Xiong et al. (2013) study how the performance of project participants affects the contractors' satisfaction in terms of client's clarity of objectives and promptness of payments, designer carefulness, construction risk management, the effectiveness of their contribution, and mutual respect and trust. Riemann and Spang (2014) study how to use execution knowledge for public financed infrastructure projects in Germany. Vaaland (2004) analyze the improving project collaboration between the contractors and the client and explores how this collaboration can be improved in different situations. Szajnfarber et al. (2010) study the effect of customer and contractor interactions on innovation in the spacecraft industry. Their research presents a preliminary model of global communication satellite innovation developed as part of an ongoing project. A model of the relationship between trust and power is developed and tested by $\mathrm{Lu}$ and Hao (2013). The model is obtained via the results of an empirical study based on a sample of Chinese contractors' cooperation. The role of collaboration in construction industry from contractors' perspectives is analyzed by Abdull Rahmana et al. (2014). They conclude that there were some major factors which can lead to willingness of collaboration among the contractors. So, they identify the views of contractors on the importance of cooperation in construction supply chain. Xu et al. (2005) indicate that prosperous collaborative partnerships and strategic alliances are needed to be developed as part of the overall strategy of the construction organization. Identification of clear purposes and objectives of partners affect the partner selection decision.

Perng et al. (2005) conclude that a subcontractor can earn even more profit if it collaborates with others in a coalition. Payoff functions for individual subcontractors and a group of subcontractors in a coalition are formulated. Profit can also be reasonably allocated to each subcontractor in a coalition using the Shapley value and nucleolus. A three-stage procedure is presented by Perng et al. (2005) to demonstrate the potential benefits of subcontractors' collaboration in a coalition. They first formulate the unit production cost with respect to daily production volume of each subcontractor. Afterwards, a job dispatching method is proposed to distribute job volume within a coalition in a cost effective manner. Finally, they suggest both the Shapley value and nucleolus approaches for examining profit allocation schemes among members of coalition. Asgari and Afshar (2008) study cooperation of subcontractors in construction projects. By applying the cooperative game theory, they show that all subcontractors have a good reason to contribute if benefits of coalition are fairly distributed. Asgari et al. (2013) focus on formulation of subcontractors' cooperation to minimize the total time. They introduce a new problem in the field of subcontractors' cooperation and then propose a model to solve it. They show that while optimizing the total cost, all subcontractors can negotiate to fairly distribute benefits from the cooperation in the core space. Most of modeling applications of the game theory in the project management have employed non-cooperative games in a static environment to solve the problems.

In the reviewed literature, none of the articles has considered the time/cost trade-off in a project. The model of Perng et al. (2005) does not concentrate on the super-additive principle. Their model has only limited numerical calculations and does not provide a discussion on how to achieve the contractors 
economic function coefficients and merely gives an assumption. The model of Asgari and Afshar (2008) does not take into account the sequence of activities and time/cost at the same time. In their model, each contractor starts its duty when previous one completes its own, and the activities must be implemented in a certain order. Thus, their model is not applicable when some of the project activities must be implemented simultaneously, or the project has some interaction activities. Based on the model presented in this paper, the subcontractors can begin their activities at the same time and they can even continue the sequence of activities related to the other one. In the other words, the activities can be interactive in this model. It is a great advantage that makes the model applicable in real projects. The paper aims to give answers to fundamental questions such as: (i) How cooperation and competition among subcontractors cause more benefit for them? (ii) How can subcontractors share resources in the cooperation game? (iii) How resulted profits will be divided among subcontractors fairly? (iv) What are the optimum cost and time in competition among subcontractors $(v)$ What is the expected project finish date? (vi) How can precedence relations among activities be modeled in a network?

Studies about cooperation among project subcontractors are limited to a small number of researchers and indicate that a subcontractor may earn even more profit if it collaborates with others. In this paper, the cooperation and competition among subcontractors are analyzed and compared according to the time/cost trade-off model presented for activities network scheduling and game theory mechanisms.

\section{Problem definition}

Competition and cooperation among subcontractors to minimize the time and cost have the most serious problems in a large scale project which should be executed by different subcontractors. Appropriate time/cost trade-off should be considered and the achieved rewards and penalties should be fairly allocated among members in cooperation games and Nash equilibrium in non-cooperative games. Time/cost trade-off problem (Vanhoucke, 2012) in project scheduling found in the critical path method (CPM) is originally based on an Activity-on-Arrow (AoA) network diagram. The time/cost trade-off model assumes direct activity cost functions to be linear functions, as shown in Fig.1. The aim is to minimize the total time considering the given budget limitations and sequence of the activities so that they can complete the project efficiently. Subcontractors can reduce the time by crashing the activities as much as possible since any unit of activities crashing would lead to an increase in the cost. The slope of the time/cost curve determines the marginal crash cost per unit of time as in Fig. 1.

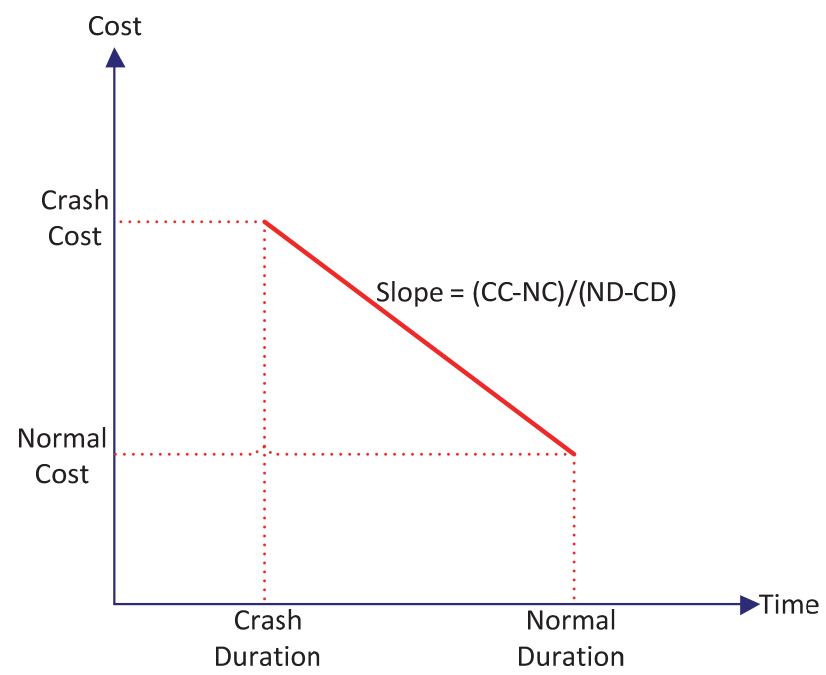

Fig.1. the time/cost trade-off of an activity

In this study, budget is considered as a resource. This implies that the cost of an individual activity is a function of its duration. That is, by spending more budgets, the activity duration will decrease. In the coalition space, the subcontractors decide to minimize the activities time with respect to their costs. In 
the competition case, the subcontractors must consider the duration of interaction activities. Thus, they choose the optimum state where all members can pay the minimum cost to fulfill minimization of the total time.

\subsection{Assumptions}

The following assumptions are introduced to specify the scope of this work for further model formulation:

1- There are $K$ subcontractors that they can be cooperative or competitive with each other according to the situations.

2- The project is divided into several sub-projects and is performed by some subcontractors.

3- Subcontractors are involved in a project and they are assumed to have rational behavior.

4- Subcontractors can perform the project in a coalition, they cooperate with each other, and they can perform competition to increase the individual profit.

5- All activities durations are compressible and the subcontractors can cooperatively conduct the activities as a coalition.

6- For every subcontractor, decision variable is the execution time for each activity. Each time has a specific cost.

7- In the competition form, interaction activities are not determined by the total project time and they are not on the critical path.

8- The information of the game is symmetric and perfect. Resources are considered in the form of budget and the subcontractors can share their available budget to cooperate.

Before we present the main model, the indices, parameters and decision variables are explained.

\subsection{Indices and sets}

$k \quad$ Set of subcontractors (i.e., players) among which the cooperation is analyzed;

$$
K=\{1,2, \ldots, k, \ldots,|k|\}
$$

$N \quad$ number of nodes (the number of events); $N=\{1,2, \ldots, n\}$

$M \quad$ Set of project activities in an AoA network. $i$ is related to starting events and $j$ is associated with ending events of an activity, $M=\{(i, j) \in N\}$

$M_{[k]} \quad$ Subset of project activities conducted by subcontractor k, $M_{[k]} \in M$

$S_{m}$ Coalition $m$ of subcontractors which form in a subset of subcontractors $K, S_{m} \in K$

\subsection{Input parameters}

$\alpha_{i j} \quad$ Slope of time/cost curve determines the marginal crash cost per unit of time;

$D_{i j[k]}^{N} \quad$ Normal duration of activity $(i, j)$ for subcontractor $k$;

$D_{i j\left[S_{m}\right]}^{N}$ Normal duration of activity $(i, j)$ for coalition $S_{m}$ of subcontractors;

$D_{i j[k]}^{C} \quad$ Crash duration of activity $(i, j)$ for subcontractor $k$;

$D_{i j\left[S_{m}\right]}^{C}$ Crash duration of activity $(i, j)$ for coalition $S_{m}$ of subcontractors;

$b_{[k]} \quad$ Budget amount available for subcontractor $k$;

$b_{[k]} \quad$ Budget amount available for coalition $S_{m}$ of subcontractors;

$C_{N} \quad$ Constant primary cost for the project. 


\subsection{Decision variables}

$y_{i j} \quad$ Number of time units that an activity $(i, j)$ is crashed into;

$X_{j} \quad$ Start time of an event (node) $j$;

\subsection{Model formulation}

The time/cost trade-off model, in the cooperation form, determines the activity durations and schedules the activities in order to minimize the project costs. It is developed for a coalition as follows:

$\min X_{n\left[S_{m}\right]}=T_{F\left[S_{m}\right]}$

subject to:

$$
\begin{array}{ll}
C_{N}+\sum_{(i, j) \in M_{\left[S_{m}\right]}} \alpha_{i j} y_{i j} \leq \sum_{k \in S_{m}} b_{[k]}, & \forall(i, j) \in M_{\left[S_{m}\right]}, \\
y_{i j} \leq D_{i j\left[S_{m}\right]}^{N}-D_{i j\left[S_{m}\right]}^{C}, & \forall(i, j) \in M_{\left[S_{m}\right]}, \\
X_{j} \geq X_{i}+D_{i j\left[S_{m}\right]}^{N}-y_{i j}, & \forall(i, j) \in M_{\left[S_{m}\right]}, \\
X_{1}=0, & \\
X_{j} \geq 0, & \\
\mathrm{y}_{\mathrm{ij}} \geq 0 . &
\end{array}
$$

Objective function (1) minimizes the total time. Constraint (2) specifies the maximum budget available for coalition. Budget restriction aims at minimizing the project duration without exceeding a given budget. Constraint (3) is related to the activities implementation time. Each activity time can be reduced to less than its normal duration, which is known as activity crashing. The value of $y_{i j}$ determines the reducing number of the normal time. Constraint (4) is the sequence of activities i.e. start time of the previous activity $j$ must be after the activity time $i$ minus the value that coalition can crash time. Constraint (5) implies that start time of the project is considered to be zero. The model can be formulated for all subcontractors' coalitions. In the cooperative models (1)-(7), the subcontractors are able to exchange their resources to reduce the project time. This Linear programming model can be solved for each coalition of subcontractors (e.g., coalition of two or three subcontractors).

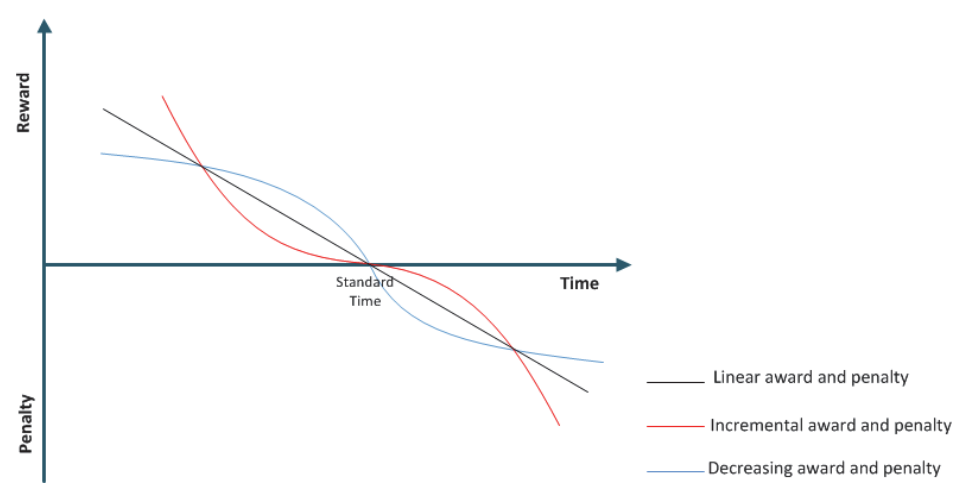

Fig. 2. Options of penalties and rewards according to the project time

In real projects, expedition and delay of the activities of subcontractors are so important for the client. Hence, reward and penalty are regularly determined by the clients in terms of the contracts. Fig. 2 
shows different options of the contract which determine the rewards or penalties according to the deadline. In Fig. 2, the function shown in red color is the incremental award and penalty; therefore, in the beginning of the project, each expedition and delay are not very important but later with each expedition, dramatic rewards will be awarded to the project and vice versa. The function shown in blue is decreasing award and penalty. That is, at the beginning of the project, any change of delay or expedition creates large penalty and reward but later, penalty and reward will be decreased. The third one is employed for the projects in which every day of delay (or expedition) makes the same penalty (or reward). In this study, the linear function is used in the numerical example which is more applicable and mathematically tractable. However, according to the project contract, the other form of penalty or reward functions can be used as well.

\section{Cooperation mechanism}

The main objective in the cooperative game theory is to determine the imputation that results in a fair allocation of the total rewards or penalties. There are various methods for sharing rewards and penalties of a cooperation that are explained in the following. First the imputation that indicates how to divide profit among players is explained.

\section{1. imputation}

Let $z_{k}$ be a real number for each $k=1,2, \ldots,|K|$, with $\sum_{k=1}^{|K|} z_{k} \leq v(K)$. A vector $\vec{z}=\left(z_{1}, \ldots, z_{k}\right)$ is an imputation if

(i) $\quad z_{k} \geq v(k)$,

(ii) $\quad \sum_{i=1}^{|K|} z_{i}=v(k)$.

Each $z_{i}$ represents the share of the value of $v(k)$ received by the player $k$. The imputation $\vec{z}$ is also called a payoff vector or an allocation, and these words will be used interchangeably.

\subsection{Core}

The core of a game provides allocations of the total penalty or the total reward that are stable, i.e. no group of activities can reasonably object to allocations in the core. The fundamental mechanism of the core is that an agreement among $N$ players can only be binding if every coalition $S \subset N$ receives collectively at least the value that it can generate or claim within the characteristic function form game, which is actually the generated value given by $v(S)$. This leads to the following definition.

A vector $\vec{z} \in R^{|K|}$ is a core allocation of the cooperative game, if $\vec{z}$ satisfies the efficiency requirement

$$
\begin{aligned}
& \sum_{k \in N} z_{k}=v(K) \\
& \sum_{k \in S} z_{k} \geq v\left(s_{m}\right) \quad \forall S \subset k
\end{aligned}
$$

\subsection{Max-Min Core}

The core offers a solution set (a space of solutions); therefore, the Max-Min Core approach can be used to present a single solution for the profit allocation. The linear programming model is as follows.

$\min \varepsilon$

subject to

$$
\begin{aligned}
& e(s, \vec{z})=v\left(s_{m}\right)-\sum_{k \in S} z_{k} \leq \varepsilon \quad \forall S \subset k, S \neq K \\
& \sum_{\forall_{k \in K}} z_{k}=V(k)
\end{aligned}
$$


Models (12)-(14) minimize the maximum dissatisfaction level of all coalitions

\subsection{Shapley value}

Shapley (1953) presented an assignment method which was based on four axioms of efficiency, symmetry, additive, and dummy property. An imputation $\vec{z}$ represents Shapley value if:

$$
z_{k}=\sum_{\substack{S_{m} \subset N \\ k \in S}} \frac{\left(\left|S_{m}\right|-1\right) !\left(|N|-\left|S_{m}\right|\right) !}{|N| !}\left\{V\left(S_{m}\right)-V\left(S_{m}-\{k\}\right)\right\}
$$

Shapley method assigns unique imputation to subcontractors depending on their role in possible coalitions.

\subsection{Equal Profit Method}

Equal profit method (EPM) is a cost allocation origin that provides a stable allocation for the players. It minimizes the maximum differences in the pairwise relative utility of players. To find this allocation, it is needed to solve the LP problem.

$$
\min f
$$

subject to:

$$
\begin{aligned}
& f \geq \frac{z_{k}}{v(\{k\})}-\frac{z_{k^{\prime}}}{v\left(\left\{k^{\prime}\right\}\right)}, \forall\left(k, k^{\prime}\right) \in K, \\
& \sum_{k \in S_{m}} z_{k} \geq v\left(S_{m}\right), \text { for all } S_{m} \subseteq K \\
& \sum_{k \in K} z_{k}=v(K) .
\end{aligned}
$$

The first constraint set measures the difference of the players' relative utility. The variable $f$ used in the objective function represents the largest difference that should be minimized. The two other constraint sets describe all stable allocations.

\subsection{Numerical examples}

The models (1)-(7) are applied for two cases that include cooperation among subcontractors with and without interaction activity. For each of them, the time/cost trade-off problems are solved.

\subsubsection{Cooperation between two subcontractors without interaction activities}

Originally, the CPM has been modeled in an AoA network representation. Fig. 2 shows an example of an AoA project network with eight non-dummy activities which are performed by two subcontractors. Node 1 is the starting event of the project and node 8 is the final event. In this example, the activities $(1,2),(2,4),(4,6)$, and $(6,8)$ are related to the subcontractor 1 and also activities $(1,3),(3,5),(5,7)$, and $(7,8)$ are related to the subcontractor 2 . 


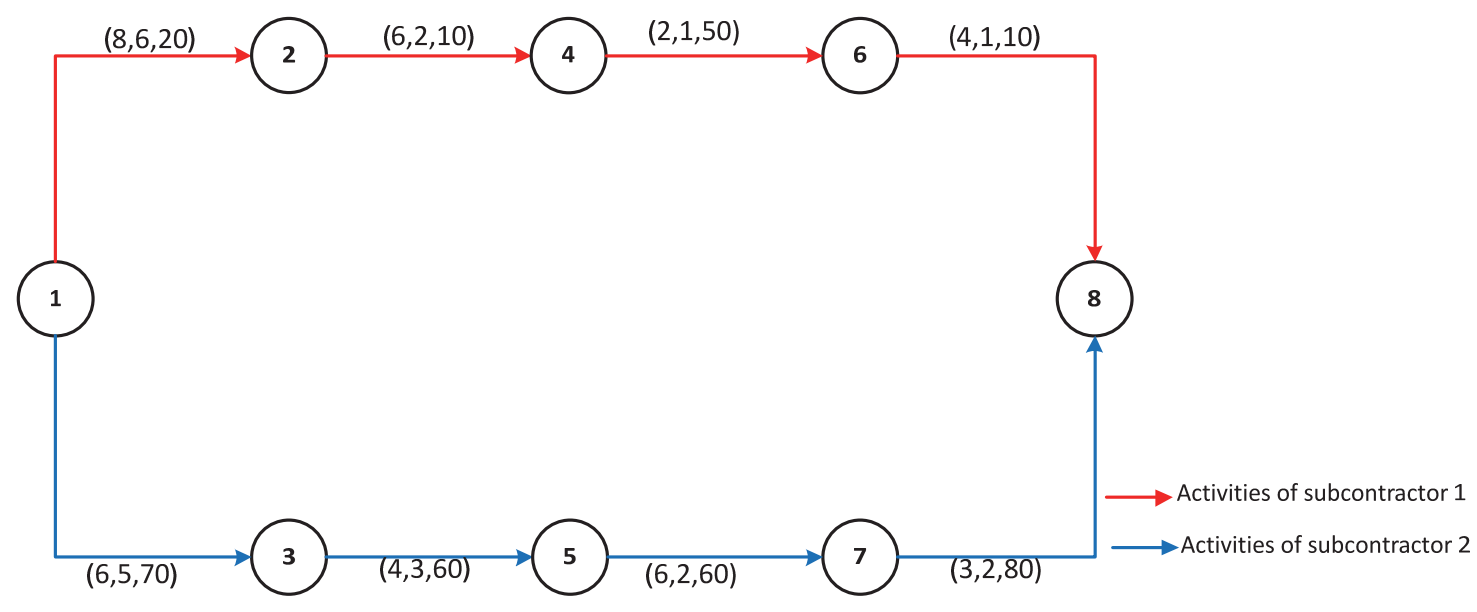

Fig. 3. AoA network for two subcontractors

As previously referred, in all three examples, the linear function is used to allocate reward and penalty over the time shown in Fig. 3. In this example, deadline is defined 17 days in a predefined contract. Every delay and expedition makes penalty and reward for the project subcontractors.

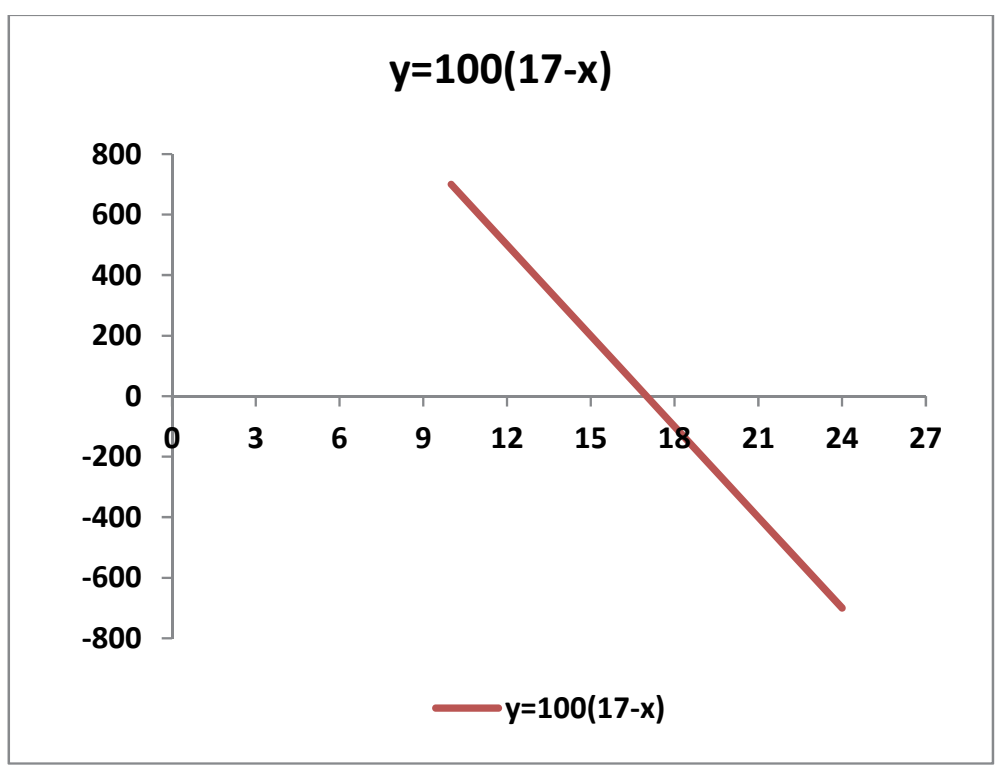

Fig. 4. Sharing penalties and rewards according to the project time for the example of this paper

Table 1

Network information for illustrative example with two subcontractors

\begin{tabular}{lcccccc}
\hline & Activity & $\begin{array}{c}\text { Normal } \\
\text { time }\end{array}$ & $\begin{array}{c}\text { Normal } \\
\text { cost }\end{array}$ & $\begin{array}{c}\text { Crash } \\
\text { time }\end{array}$ & $\begin{array}{c}\text { Crash } \\
\text { cost }\end{array}$ & $\boldsymbol{\alpha}_{\boldsymbol{i j}}$ \\
\hline \multirow{3}{*}{ Subcontractor 1 } & $(1,2)$ & 8 & 20 & 6 & 60 & 20 \\
& $(2,4)$ & 6 & 40 & 2 & 80 & 10 \\
& $(4,6)$ & 2 & 50 & 1 & 100 & 50 \\
Subcontractor 2 & $(6,8)$ & 4 & 30 & 1 & 60 & 10 \\
& $(1,3)$ & 6 & 220 & 2 & 400 & 70 \\
& $(3,5)$ & 4 & 140 & 3 & 200 & 60 \\
& $(5,7)$ & 6 & 60 & 2 & 300 & 60 \\
& $(7,8)$ & 3 & 20 & 2 & 100 & 80 \\
\hline
\end{tabular}


The problem is solved with the information of Table 1. In fact, this model was solved three times. First, it was calculated individually for the subcontractors $\{1\}$ and $\{2\}$ and then was calculated for the coalition $\{1,2\}$. The results are demonstrated in the Table 2 .

Table 2

Value of characteristic function for coalitions with two subcontractors

\begin{tabular}{llll}
\hline Coalition & $\{1\}$ & $\{2\}$ & $\{1,2\}$ \\
\hline Available budget & 230 & 230 & 460 \\
Objective value (T) & 10 & 16 & 13 \\
Project time (T) & 16 & 16 & 13 \\
Time reduction & 1 & 1 & 4 \\
Reward and Penalty & 100 & 100 & 400 \\
$\quad \boldsymbol{y}=\mathbf{1 0 0}(\mathbf{2 1}-\boldsymbol{x})$ & & & \\
\hline
\end{tabular}

Project time in Table 2 is measured in terms of maximum finished activity time. Also, the values of reward and penalty in Table 2 are calculated in accordance with the predefined contract. It is assumed that the reward and penalty function is according to the function of Fig. 3. The deadline is assumed 17 days and each delay or expedition makes 100 units of penalties or rewards.

\section{Table 3}

Cooperation mechanisms with two subcontractors

\begin{tabular}{llll}
\hline \multicolumn{4}{c}{ Cooperation Mechanisms } \\
\hline Subcontractor1 & Shapley value & Max-min Core & EUM \\
\hline Subcontractor2 & 150 & 300.0000 & 100.0000 \\
\hline
\end{tabular}

As shown in Table 3, various cooperation mechanisms can lead to different results. Hence, according to the contract type and the profit share methods (e.g. cooperative mechanisms), the profit assigned to each subcontractor can be thoroughly specified. The mathematical model based on the EPM can now be stated as:

$\min f$

subject to:

$f \geq \frac{z_{1}}{100}-\frac{z_{2}}{100}$

$z_{1} \geq 100$

$z_{2} \geq 100$

$400-z_{1}-z_{2}=0$

The Min-Max core can be stated as follows:

$\min \varepsilon$

$100-z_{1} \leq \varepsilon$

$100-z_{2} \leq \varepsilon$

$z_{1}+z_{2}=400$ 
$z_{1} \geq 0$

$z_{2} \geq 0$

In Table $1 \alpha_{i j}$ is calculated as in Eq. (8) which is the slope of the time/cost curve. As Table 2 shows, both subcontractors make more awards for the coalition $(\{1,2\})$. So, it makes great incentives to organize a coalition. The fair and efficient shares of the two players are presented in Table 3; and the space of Core is shown in Fig. 4 for this model. As shown in Fig. 5, the core space is the gray segment that shows the proper imputations.

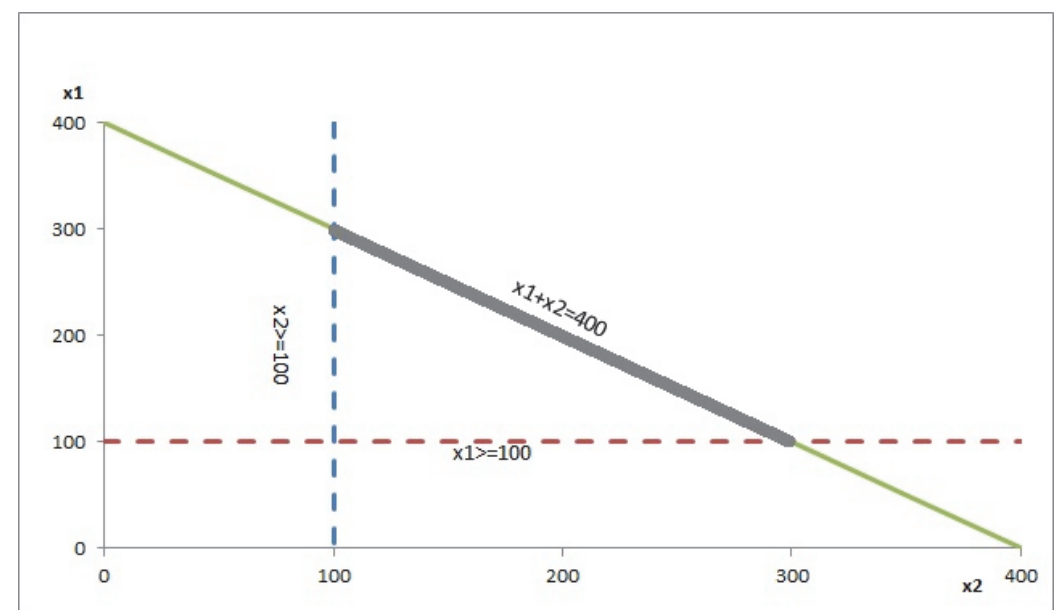

Fig. 5. Space of Core for two subcontractors

\subsubsection{An competition between two subcontractors with interaction activities}

The meaning of interaction activities is the subcontractor's activities which are interrelated with each other. For example, the activities continuation of subcontractor 1 is conducted by subcontractor 2 . Subcontractor's strategies arise by changing duration of the interaction activities. This problem is solved with non-cooperative game theory approaches. Fig. 6 shows the AoA network with 10 activities. Activities $(1,2),(2,5),(2,4),(4,6)$, and $(6,8)$ belong to subcontractor 1 ; and the others belong to subcontractor 2 . The network information is illustrated in Table 4.

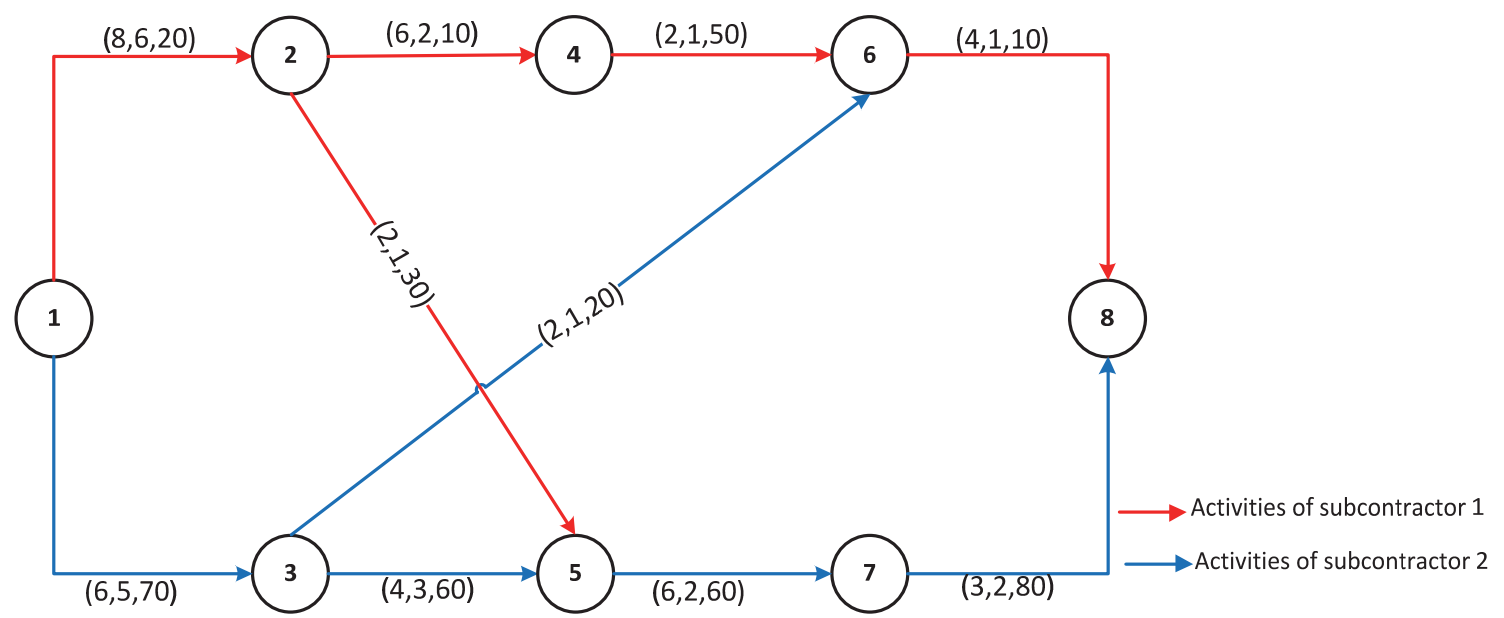

Fig. 6. AoA network for two subcontractors with interaction activities 
Table 4

Network information of the illustrative example with three subcontractors

\begin{tabular}{lllllll}
\hline & Activity & $\begin{array}{l}\text { Normal } \\
\text { time }\end{array}$ & $\begin{array}{l}\text { Normal } \\
\text { cost }\end{array}$ & Crash time & $\begin{array}{l}\text { Crash } \\
\text { cost }\end{array}$ & $\boldsymbol{\alpha}_{\boldsymbol{i j}}$ \\
\hline \multirow{5}{*}{ Subcontractor 1 } & $(1,2)$ & 8 & 20 & 6 & 60 & 20 \\
& $(2,5)$ & 2 & 30 & 1 & 60 & 30 \\
& $(2,4)$ & 6 & 40 & 2 & 80 & 10 \\
& $(4,6)$ & 2 & 50 & 1 & 100 & 50 \\
Subcontractor 2 & $(6,8)$ & 4 & 30 & 1 & 60 & 10 \\
& $(3,3)$ & 6 & 220 & 5 & 400 & 70 \\
& $(3,6)$ & 2 & 30 & 1 & 50 & 20 \\
& $(5,7)$ & 6 & 140 & 3 & 200 & 60 \\
& $(7,8)$ & 3 & 60 & 2 & 300 & 60 \\
\end{tabular}

The model for Subcontractor 1 is as follow: The model for Subcontractor 2 is as follow:

$$
\begin{aligned}
& \min x_{8} \\
& 20 y_{12}+10 y_{24}+50 y_{46}+10 y_{68}+ \\
& 70 y_{13}+20 y_{36}+30 y_{25} \leq 500 \\
& y_{12} \leq 2 \\
& y_{24} \leq 4 \\
& y_{46} \leq 1 \\
& y_{68} \leq 3 \\
& y_{13} \leq 1 \\
& y_{36} \leq 1 \\
& y_{25} \leq 1 \\
& x_{1}=0 \\
& x_{2} \geq x_{1}+8-y_{12} \\
& x_{4} \geq x_{2}+6-y_{24} \\
& x_{5} \geq x_{2}+2-y_{25} \\
& x_{6} \geq x_{4}+2-y_{46} \\
& x_{8} \geq x_{6}+4-y_{68} \\
& x_{3} \geq x_{1}+6-y_{13} \\
& x_{6} \geq x_{3}+2-y_{36} \\
& \sum_{i=1}^{8} x_{i} \geq 0 \\
& \sum y_{i j} \geq 0 \\
& \min x_{8} \\
& 20 y_{12}+70 y_{13}+60 y_{35}+60 y_{57}+ \\
& 80 y_{78}+30 y_{25}+20 y_{36} \leq 500 \\
& y_{12} \leq 2 \\
& y_{13} \leq 1 \\
& y_{35} \leq 1 \\
& y_{57} \leq 4 \\
& y_{78} \leq 1 \\
& y_{25} \leq 1 \\
& y_{36} \leq 1 \\
& x_{1}=0 \\
& x_{2} \geq x_{1}+8-y_{12} \\
& x_{3} \geq x_{1}+6-y_{13} \\
& x_{5} \geq x_{3}+4-y_{35} \\
& x_{7} \geq x_{5}+6-y_{57} \\
& x_{8} \geq x_{7}+3-y_{78} \\
& x_{5} \geq x_{2}+2-y_{25} \\
& x_{6} \geq x_{3}+2-y_{36} \\
& \sum_{i=1}^{8} x_{i} \geq 0 \\
& \sum y_{i j} \geq 0
\end{aligned}
$$


Table 6

The payoff matrix for the identified equilibrium point

\begin{tabular}{|c|c|c|c|c|}
\hline & $\begin{array}{l}y_{13}=0 \\
y_{36}=0\end{array}$ & $\begin{array}{l}y_{13}=1 \\
y_{36}=0\end{array}$ & $\begin{array}{l}y_{13}=0 \\
y_{36}=1\end{array}$ & $\begin{array}{l}y_{13}=1 \\
y_{36}=1\end{array}$ \\
\hline $\begin{array}{l}y_{12}=0 \\
y_{25}=0\end{array}$ & $(12,14)$ & $(12,14)$ & $(12,14)$ & $(12,14)$ \\
\hline $\begin{array}{l}y_{12}=1 \\
y_{25}=0\end{array}$ & $(11,13)$ & $(11,13)$ & $(11,13)$ & $(11,13)$ \\
\hline $\begin{array}{l}y_{12}=2 \\
y_{25}=0\end{array}$ & $(10,13)$ & $\left(10^{*}, 12^{*}\right) 160,450$ & $(10,13)$ & $\left(10^{*}, 12^{*}\right) 160,470$ \\
\hline $\begin{array}{l}y_{12}=0 \\
y_{25}=1\end{array}$ & $(12,13)$ & $(12,13)$ & $(12,13)$ & $(12,13)$ \\
\hline $\begin{array}{l}y_{12}=1 \\
y_{25}=1\end{array}$ & $(11,13)$ & $(11,12)$ & $(11,13)$ & $(11,12)$ \\
\hline $\begin{array}{l}y_{12}=2 \\
y_{\mathbf{2 5}}=1\end{array}$ & $(10,13)$ & $\left(10^{*}, 12^{*}\right) 190,450$ & $(10,13)$ & $\left(10^{*}, 12^{*}\right) 190,470$ \\
\hline
\end{tabular}

Table 6 is the payoff matrix for the identified equilibrium point. Each matrix cell consists of two numbers. The first number in each cell is the payoff to the row player (subcontractor 1), and the second number is the payoff to the column player (subcontractor 2). It is assumed that each player applies the "sure-thing" principle: it maximizes its minimum payoff by determining the minimum it will receive whatever its opponent does. Thereby, subcontractor 1 finds that it will do best to choose strategy 1 no matter what subcontractor 2 does: if subcontractor 2 chooses $i$, subcontractor 1 will get 3 and 6 regardless of what subcontractor 1 does; if subcontractor 2 chooses $i i$, subcontractor 1 will get 3 and 6 again. If subcontractor 2 chooses $i i i$ and $i v$, subcontractor 1 will get 3 and 6 . Subcontractor 2 similarly finds that it will do best to choose $i$ no matter what subcontractor 1 does. This matrix has 4 Nash equilibrium points.

(i) The critical path defines the total time in each cell.

(ii) Increasing $y_{i j}$ decreases to somewhat the path time but there may be another path that will be the critical path which makes the total time fixed or even increased.

(iii) The solution of a cooperative game, in which the players have a common goal, includes coordinating the players' decisions in an effective manner. This is relatively obvious, as the solution finding for the constant-sum games with a saddle point. For games in which the players have both common and conflicting goals - in other words, in most variable-sum games, whether cooperative or noncooperative - what forms a solution is much harder to define and make convincing.

(iv) There are 4 Nash-equilibrium points in the payoff matrix for the example. But each of them has a specific cost for the subcontractors. Minimum cost is related to $\left(y_{13}=1\right.$ and $y_{36}=0, y_{12}=2$ and $\left.y_{25}=0\right)$ the one that has 160 units of cost for subcontractor 1 and 450 units for the other one. There can be 30 units of cost saving for subcontractor 1 and 20 units of cost saving for subcontractor 2 .

(v) If an interaction activity for a subcontractor will be a critical path, it makes a constant objective function value for the other subcontractor with different strategy. So, for better display of the interaction activity concept application, an example in which the interaction activities are not determined by the total time is studied because the other subcontractor can have a different result by selecting different strategies. 
Table 7

The matrix of Nash bargaining payoffs

\begin{tabular}{ccccc}
\hline $\boldsymbol{Z}$ & $\begin{array}{c}\boldsymbol{y}_{\mathbf{1 3}}=0 \\
\boldsymbol{y}_{\mathbf{3 6}}=0\end{array}$ & $\begin{array}{c}\boldsymbol{y}_{\mathbf{1 3}}=1 \\
\boldsymbol{y}_{\mathbf{3 6}}=0\end{array}$ & $\begin{array}{c}\boldsymbol{y}_{\mathbf{1 3}}=0 \\
\boldsymbol{y}_{\mathbf{3 6}}=1\end{array}$ & $\begin{array}{c}\boldsymbol{y}_{\mathbf{1 3}}=1 \\
\boldsymbol{y}_{\mathbf{3 6}}=1\end{array}$ \\
\hline $\boldsymbol{y}_{\mathbf{1 2}}=0$ & $(2 \times 2)=4$ & $(2 \times 2)=4$ & $(2 \times 2)=4$ & $(2 \times 2)=4$ \\
$\boldsymbol{y}_{\mathbf{2 5}}=0$ & & & & $(1 \times 1)=1$ \\
$\boldsymbol{y}_{\mathbf{1 2}}=1$ & $(1 \times 1)=1$ & $(1 \times 1)=1$ & $(1 \times 1)=1$ & \\
$\boldsymbol{y}_{\mathbf{2 5}}=0$ & & & & $(0 \times 0)=0^{*}$ \\
$\boldsymbol{y}_{\mathbf{1 2}}=2$ & $(0 \times 1)=0^{*}$ & $(0 \times 0)=0^{*}$ & $(0 \times 1)=0^{*}$ & $(2 \times 1)=2$ \\
$\boldsymbol{y}_{\mathbf{2 5}}=0$ & & & & \\
$\boldsymbol{y}_{\mathbf{1 2}}=0$ & $(2 \times 1)=2$ & $(2 \times 1)=2$ & $(2 \times 1)=2$ & $(1 \times 0)=0^{*}$ \\
$\boldsymbol{y}_{\mathbf{2 5}}=1$ & & & & \\
$\boldsymbol{y}_{\mathbf{1 2}}=1$ & $(1 \times 1)=1$ & $(1 \times 0)=0^{*}$ & $(1 \times 1)=1$ & $(0 \times 0)=0^{*}$ \\
$\boldsymbol{y}_{\mathbf{2 5}}=1$ & & & & \\
$\boldsymbol{y}_{\mathbf{1 2}}=2$ & $(0 \times 1)=0^{*}$ & $(0 \times 0)=0^{*}$ & $(0 \times 1)=0^{*}$ & \\
$\boldsymbol{y}_{\mathbf{2 5}}=1$ & & & & \\
\hline
\end{tabular}

\section{Nash-bargaining}

The Nash-bargaining solution makes 8 results but the point $\left(y_{13}=1\right.$ and $y_{36}=0, y_{12}=2$ and $\left.y_{25}=0\right)$ is better due to less cost.

$\max \prod_{i=1}^{N}\left(Z_{i}-p_{i}\right)$

Subject to:

$$
\begin{aligned}
& z_{i} \geq p_{i} \\
& z_{i} \leq z_{i}^{*}
\end{aligned}
$$

where:

$z_{i}:$ is the payoff function for player $i$

$p_{i}$ : is the minimum payoff needed for player $i$

$N$ : is the number of player

$z_{i}^{*}$ : is the maximum payoff for player $i$ when he played individually.

$$
p_{1}=10 \text { and } p_{2}=12
$$

\section{Conclusion}

Cooperation and competition in different situations have different results. Most large-scale projects include several subprojects which are carried out by distinct subcontractors. Subcontractors can cooperate with each other and can compete. Scheduling and budget allocation in the projects is very important. Allocated time to the subcontractors according to the predefined contract may not be the optimal time because there are some restrictions which subcontractors are involved. These restrictions affect the available budget, work efficiency, total cost and time, and reward or penalty of the subcontractors. The time and cost restrictions must be considered simultaneously because these factors affect each other. This issue was highlighted when several subcontractors cooperate by sharing their budgets. A linear programing model is proposed for subcontractors' cooperation and it is considered that all restrictions will be affected. In this paper, some mechanisms are suggested for cooperation and fair profit allocation. In the coalition state, subcontractors may evaluate optimal time that consequently decreases the total cost and increases the rewards. The results of the research show that subcontractors have in- 
centive for form coalition, and perform the project cooperatively. They must use an appropriate schedule, consider different conditions together, consider cooperation mechanisms to allocate rewards and penalties, consider time/cost trade off model, and take into account start and finish time of the subprojects. By distributing benefits of coalition fairly, all subcontractors have a good reason to contribute. In comparison to Asgari (2013), this paper has developed a cooperative game theory model for time/cost trade-off problem of a set of subcontractors and can be used easily in projects and address the competition among subcontractors. It also considers the competition and cooperation for project subcontractors.

There are some subjects for further research: Considering the uncertainty factors (e.g. fuzzy and stochastic) which make the results more real. Considering the game among 3 or more players and achieving the Three-dimensional payoff matrix for them. Considering the human resource and consumption resource separately can be useful for develop the model.

\section{References}

Arsenyan, J., Büyüközkan, G., \& Feyzioğlu, O. (2015). Modeling collaboration formation with a game theory approach. Expert Systems with Applications, 42(4), 2073-2085.

Asgari, M. S., \& Afshar, A. (2008, August). Modeling subcontractors cooperation in time; cooperative game theory approach. In First International Conference on Construction in Developing Countries (ICCIDC-I) (pp. 312-319).

Asgari, S., Afshar, A., \& Madani, K. (2013). Cooperative game theoretic framework for joint resource management in construction. Journal of Construction Engineering and Management, 140(3), 04013066.

Brânzei, R., Ferrari, G., Fragnelli, V., \& Tijs, S. (2002). Two approaches to the problem of sharing delay costs in joint projects. Annals of Operations Research, 109(1-4), 359-374.

Cakmak, P. I., \& Tas, E. (2012). Strategic planning practices of contractor firms in Turkey. ProcediaSocial and Behavioral Sciences, 58, 40-46.

Canegallo, C., Ortona, G., Ottone, S., Ponzano, F., \& Scacciati, F. (2008). Competition versus cooperation: Some experimental evidence. The Journal of socio-economics, 37(1), 18-30.

Estévez-Fernández, A., Borm, P., \& Hamers, H. (2007) Project games International Journal of Game Theory. Volume, 36, 149-176.

Estévez-Fernández, A. (2012). A game theoretical approach to sharing penalties and rewards in projects. European Journal of Operational Research, 216(3), 647-657.

Kadefors, A. (2004). Trust in project relationships - inside the black box. International Journal of project management, 22(3), 175-182.

Lozano, S., Moreno, P., Adenso-Díaz, B., \& Algaba, E. (2013). Cooperative game theory approach to allocating benefits of horizontal cooperation. European Journal of Operational Research, 229(2), 444-452.

Lu, S., \& Hao, G. (2013). The influence of owner power in fostering contractor cooperation: Evidence from China. International Journal of Project Management, 31(4), 522-531.

Mouritsen, J. (1999). The flexible firm: strategies for a subcontractor's management control. Accounting, Organizations and society, 24(1), 31-55.

Parrod, N., Thierry, C., Fargier, H., \& Cavaille, J. B. (2007). Cooperative subcontracting relationship within a project supply chain: A simulation approach. Simulation Modelling Practice and Theory, 15(2), 137-152.

Perng, Y. H., Chen, S. J., \& Lu, H. J. (2005). Potential benefits for collaborating formwork subcontractors based on co-operative game theory. Building and Environment, 40(2), 239-244.

Rahman, S. H. A., Endut, I. R., Faisol, N., \& Paydar, S. (2014). The Importance of Collaboration in Construction Industry from Contractors' Perspectives. Procedia-Social and Behavioral Sciences, 129, 414-421. 
Riemann, S., \& Spang, K. (2014). Application of Contractor's Knowledge in Public Financed Infrastructure Projects in Germany. Procedia-Social and Behavioral Sciences, 119, 202-209.

Segal, N. L., \& Hershberger, S. L. (1999). Cooperation and competition between twins: Findings from a prisoner's dilemma game. Evolution and Human Behavior, 20(1), 29-51.

Shapley, L. S. (1953). A value for n-person games. Annals of Mathematics Studies, 28, 307-317.

Suprapto, M., Bakker, H. L., Mooi, H. G., \& Moree, W. (2015). Sorting out the essence of ownercontractor collaboration in capital project delivery. International Journal of Project Management, 33(3), 664-683.

Szajnfarber, Z., Stringfellow, M. V., \& Weigel, A. L. (2010). The impact of customer-contractor interactions on spacecraft innovation: Insights from communication satellite history. Acta Astronautica, 67(9), 1306-1317.

Vaaland, T. I. (2004). Improving project collaboration: start with the conflicts. International Journal of Project Management, 22(6), 447-454.

Vanhoucke, M. (2012). Project management with dynamic scheduling. Springer Berlin Heidelberg.

Xiong, B., Skitmore, M., Xia, B., Masrom, M. A., Ye, K., \& Bridge, A. (2014). Examining the influence of participant performance factors on contractor satisfaction: A structural equation model. International Journal of Project Management, 32(3), 482-491.

$\mathrm{Xu}, \mathrm{T}$., Bower, D. A., \& Smith, N. J. (2005). Types of collaboration between foreign contractors and their Chinese partners. International Journal of Project Management, 23(1), 45-53.

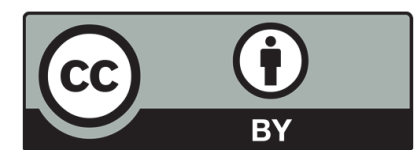

(C) 2017 by the authors; licensee Growing Science, Canada. This is an open access article distributed under the terms and conditions of the Creative Commons Attribution (CC-BY) license (http://creativecommons.org/licenses/by/4.0/). 